\title{
Characteristics of migration and speciation of trace elements during co-processing of antibiotic residues in a circulating fluidized bed
}

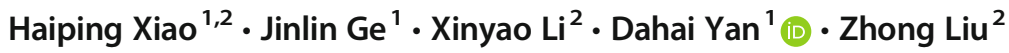 \\ Received: 22 May 2020 / Accepted: 18 May 2021 / Published online: 12 June 2021 \\ (C) The Author(s), under exclusive licence to Springer-Verlag GmbH Germany, part of Springer Nature 2021
}

\begin{abstract}
In order to study the emission characteristics of the products during the blending of antibiotic residues in coal-fired power plants, blending tests were performed on a $140 \mathrm{t} / \mathrm{h}$ circulating fluidized bed boiler. It was found that during combustion, 64 to $87.6 \%$ of $\mathrm{Cr}, \mathrm{As}$, and $\mathrm{Pb}$ are concentrated in the fly ash, and 11.4 to $35 \%$ are concentrated in the bottom ash. Only a small amount of these elements are captured by the desulfurization system or enter the environment. During the material distribution of the desulfurization system, trace elements are mostly concentrated in gypsum. In the desulfurization system, the proportion of $\mathrm{Cr}, \mathrm{As}, \mathrm{Pb}, \mathrm{Be}$, $\mathrm{Mn}, \mathrm{Co}, \mathrm{Ni}, \mathrm{Se}$, and Mo in the gypsum range from 82.8 to $99.9 \%$, and the content has reached the level of ppm. When the blending ratio is controlled within $7 \%$, the blending of antibiotic residues has little effect on the elemental composition of coal. The contents of $\mathrm{Cr}, \mathrm{Ni}, \mathrm{Cu}, \mathrm{Zn}$, and $\mathrm{Ba}$ in the products increased by 9.5 to $22.3 \%$. This may mean when the blending ratio is increased, it will be harmful to the environment.
\end{abstract}

Keywords Circulating fluidized bed $\cdot$ Desulfurization $\cdot$ Distribution $\cdot$ Environmental risk $\cdot$ Trace element

\section{Introduction}

With the acceleration of industrialization, the discharge of hazardous wastes increases rapidly. The preliminary estimate of hazardous waste production in China in 2019 is 94.08 million tons. Compared with the huge amount of hazardous waste generated, China's hazardous waste treatment capacity is seriously insufficient. In 2020, affected by the outbreak of the coronavirus during the Chinese New Year, it is estimated that the output of medical waste in China will increase by more than $20 \%$. It is estimated that the output of hazardous waste in China will be driven by the growth of the output of medical waste in 2020, or more than 100 million tons(National bureau

Responsible Editor: Philippe Garrigues

Dahai Yan

seavsland@163.com

$1 \quad$ State Key Laboratory of Environmental Criteria and Risk Assessment, Chinese Research Academy of Environmental Sciences, Beijing 100012, China

2 School of Energy, Power and Mechanical Engineering, North China Electric Power University, Beijing 102206, China of statistics 2018). Sources of hazardous waste are relatively common, mainly from the waste liquid, waste residue, sludge produced by the paper industry, chemical plant sludge, petrochemical sludge, laboratory organic waste liquid, industrial organic waste liquid, and medical waste. The hazardous waste treatment technologies mainly include physical treatment (Tong et al. 2019), chemical treatment, and biological treatment, and the final waste disposal technologies include landfill, incineration technology, surface treatment, and marine disposal (Wang 2017; Liu 2014). Because of the shortage of land resources, incineration technology is currently the most effective method for large-scale hazardous waste treatment. It can completely eliminate the toxicity and hazards of waste while reducing the volume of hazardous waste to the greatest extent (Zhao et al. 2002; Sandelin and Backman 2001). At present, research and practical operation of industrial boilers for incineration of hazardous wastes are mainly circulating fluidized bed boilers and pulverized coal furnaces.

Due to the uneven diameter of the antibiotic residue, the discharge may exceed the standard during the operation of the circulating fluidized bed. At the same time, the material in the fluidized bed boiler has the characteristics of high concentration and high wind speed (Jiang et al. 2020), which leads to serious wear of the boiler components. In comparison, the 
circulating fluidized bed has more advantages for solid waste disposal. During the combustion of the circulating fluidized bed, in order to prevent the environmental pollution caused by the leakage of hazardous waste, the furnace is maintained to operate at a negative pressure of 30-50Pa (Liu et al. 2020). Due to the strong adaptability of the circulating fluidized bed to the materials entering the furnace, it has perfect combustion performance for hazardous wastes with high moisture content and low heating value (Zhu et al. 2019). During the combustion process, the bed material has a large contact area and a long residence time, which can effectively pyrolyze hazardous waste. At the same time, the low-temperature, staged combustion used in the circulating fluidized bed can effectively limit the harmful gases generated during the combustion of hazardous waste. Therefore, the circulating fluidized bed is more suitable for the co-processing of hazardous waste.

The content of trace elements in hazardous wastes is quite different from that in coals. During the co-processing process, it may lead to changes in the distribution and enrichment of trace elements or an increase in pollutants in the flue gas. The discharge of trace elements in coal and its harm to the environment become an issue of increasing concern. Studying the characteristics of migration and speciation of trace elements in the combustion process can lay the foundation for the clean utilization of coal in the study area. Liu et al. (2009) studied the combustion characteristics, flue gas emissions, and ash and slag emissions in a CFB simulation test bench under co-processing of sludge and coal water slurry. The results show that the content of trace elements $\mathrm{As}, \mathrm{Cd}, \mathrm{Cr}, \mathrm{Cu}, \mathrm{Co}, \mathrm{Ni}, \mathrm{Pb}$, and $\mathrm{Zn}$ in the bottom ash and fly ash after blending with oil sludge is lower than the standard line, and it can be used as cultivated soil recycling. Zhu et al. (2009) studied the emission characteristics of trace elements $\mathrm{Hg}, \mathrm{Pb}, \mathrm{Ni}, \mathrm{Cr}, \mathrm{Cu}$, and $\mathrm{Zn}$ in the cocombustion process of petrochemical sludge and coal on a $0.2 \mathrm{MW}$ pilot-scale circulating fluidized bed experimental bench, and found that when the mass ratio of petrochemical sludge to coal increased from 10 to $40 \%, \mathrm{Hg}$ and $\mathrm{Zn}$ emissions increased, while $\mathrm{Pb}$ and $\mathrm{Ni}$ emissions decreased. Duan et al. (2017) studied the distribution rule of arsenic during the co-processing of petroleum coke by three $440 \mathrm{t} / \mathrm{h}$ circulating fluidized bed boilers, and found that As mainly exists in electrostatic dust removal and bag dust removal, accounting for 17.4 to $37.5 \%$ and 55.6 to $77.5 \%$, respectively. Morphological analysis shows that $\mathrm{As}^{5+}$ is the main watersoluble substance in the incoming fuel, bottom ash, and fly ash, while $\mathrm{As}^{3+}$ is the main water-soluble substance in wet flue gas desulfurization (WFGD) wastewater. Dong et al. (2015) carried out experiments on co-combustion of coal and tannery sludge on a $35-\mathrm{kW}$ fluidized bed burner, studied the combustion process and emission characteristics of the fuel, and found that due to the long residence time of the fuel in the high temperature area of the furnace, the oxidation degree of $\mathrm{Cr}$ in ash is high, and $\mathrm{CrO}_{3}$ and $\mathrm{CrO}_{2}(\mathrm{OH})_{2}$ are mainly produced.
In this paper, the antibiotic residues are divided into wet antibiotic residues before drying and dry residues after drying. Residues are added under different working conditions. The sampling and analysis of the material in and out of circulating fluidized bed mixed with antibiotic residue are carried out to explore the migration and occurrence of various heavy metals in the combustion process. This paper can provide some data and theoretical basis for the effective control of trace element emission.

\section{Test object and analysis method}

\section{Basic conditions of the test}

This test was carried out in a $140 \mathrm{t} / \mathrm{h}$ circulating fluidized bed boiler in Shandong province. The boiler flue gas desulfurization project (FGD) uses a limestone-gypsum wet desulfurization process. Figure 1 shows a circulating fluidized bed system diagram:

There are three fuel sampling points in the furnace. The first is the belt under the coal bunker, which is the sampling point of dry coal slime or a mixture of dry coal slime and dry antibiotic residues; the second is mixing chambers, which are sampling points for coal water slurry or coal water slurry and wet antibiotic residues; the third sampling point is the outlet of the lime tank. Dry antibiotic residues and wet antibiotic residues are sampled separately before blending. There are three solid samples taken out of the furnace. Fly ash is sampled at the outlet of the ash storehouse, bottom ash is sampled at the boiler slag outlet, and gypsum is sampled at the belt of the vacuum filter, as shown in Fig. 2.

\section{Analysis of raw coal}

The antibiotic residue during the co-processing process comes from a local pharmaceutical factory. The residue is the mixed bacteria residue in the purification process of the raw material medicine. It contains four antibiotics: kanamycin, abamectin, salinomycin, and monensin. The antibiotic residues are classified as pharmaceutical wastes in China's "National Hazardous Waste List," and their hazardous characteristics are T-level (toxicity). The field test is divided into three working conditions: blank working condition, wet drug residue working condition, and dry drug residue working condition. During the test, the mass ratio of dry coal slime and coal water slurry was stable at 6:4, the boiler load was stable at $100 \mathrm{t} / \mathrm{h}$, and the test time under different conditions was $8 \mathrm{~h}$. Under the condition of wet medicine slag, the blending ratio of wet medicine slag and wet slime is stable at 1:15, and under the condition of dry medicine slag, the blending ratio of dry medicine slag and dry slime is stable at 1:20. 
Fig. 1 CFB system diagram

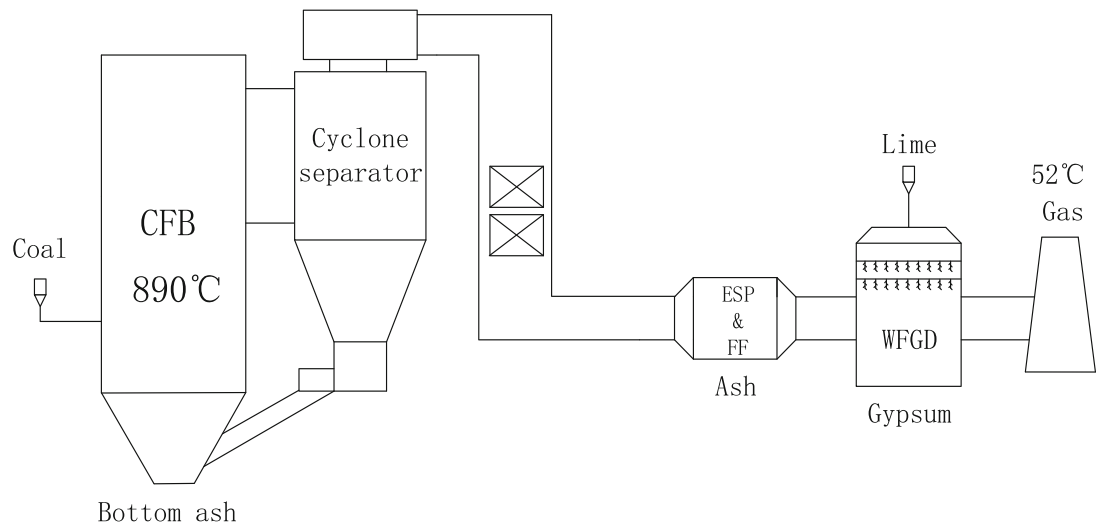

The industrial analysis and calorific value of the incoming coal and antibiotic residue are shown in Table 1.The reference standard for industrial analysis is GBT212-2008 and for calorific value is GB213-87.

According to the data in Table 1, the volatile content of antibiotic residues is relatively high. Especially in dry residues, volatiles account for $53.01 \%$ of the total solids, and the fixed carbon content is lower than $8.6 \%$. The dried slag has a large calorific value, reaching $12.69 \mathrm{MJ} / \mathrm{kg}$, and its high volatility ensures the combustion performance in the furnace, which can be used as an excellent alternative fuel.

Table 2 shows the content of each trace element in the furnace material during the test. The contents of trace elements $\mathrm{Cr}, \mathrm{As}, \mathrm{Pb}, \mathrm{Mn}, \mathrm{Ni}$, and $\mathrm{Mo}$ all reached the ppm level. The contents of $\mathrm{Cr}, \mathrm{Mn}, \mathrm{Co}$, and $\mathrm{Ni}$ in the residue are similar to the corresponding heavy metal content in raw coal.

Samples of coal (dry coal slime and coal slurry), antibiotic residues (dry antibiotic residues and wet antibiotic residues), quicklime, fly ash, gypsum, desulfurized wastewater, and flue gas were sampled at $2 \mathrm{~h}$ and $6 \mathrm{~h}$ after the test started. The smoke sampling method refers to USEPA Method 2. The smoke sampling for each working condition lasts for $1 \mathrm{~h}$, and the sampling point is the section of the chimney discharge port, during which the operating conditions parameters are kept stable.

\section{Digestion experiment}

The samples collected during the test were brought back to the laboratory for analysis. The reagents used in the test were loaded with national standard premium grade pure (GR) chemical reagents, and the experimental water was freshly prepared deionized water. The retrieved samples were analyzed using an inductively coupled plasma mass spectrometer (ICP-MS), model Agilent 7500a. During the experiment, $0.1 \sim 0.2 \mathrm{~g}$ of the sample was weighed back, and $1 \mathrm{ml}$ of hydrochloric acid (superior pure $1.19 \mathrm{~g} / \mathrm{ml}$ ), $1 \mathrm{ml}$ of hydrogen peroxide $(30 \%)$, and $4 \mathrm{ml}$ of nitric acid (superior pure 1.42 $\mathrm{g} / \mathrm{ml}$ ) were added. The electric heating plate is heated at a low temperature of $120^{\circ} 2$. When the solution in the digestion tank is brought to $3 \mathrm{ml}$, it is removed and cooled. After adding $5 \mathrm{ml}$ of nitric acid to cover, it is heated on a hotplate at $180^{\circ} \mathrm{e}$. The digestion tank is placed on an acid drive instrument at $150^{\circ}$. Heat the acid until the content of the soy is the size of soybeans. Transfer the solution to a 50-ml volumetric flask and filter with qualitative filter paper in the middle. During the experiment, a blank group and a blank spiking group are added, which are detected after the same test steps as the sample to be tested, to prevent the trace elements in the reagent from affecting the experimental results.

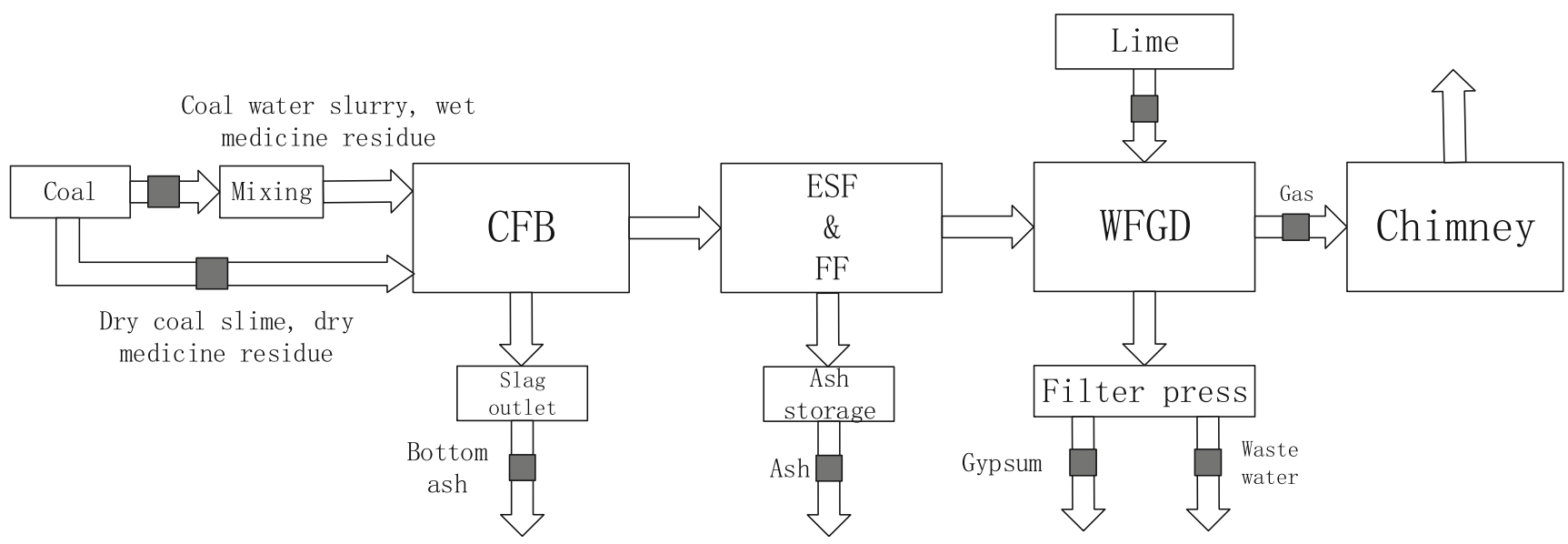

Fig. 2 Location of sampling points 
Table 1 Industrial analysis and low calorific value of incoming coal and biotin residue

\begin{tabular}{|c|c|c|c|c|c|c|c|}
\hline Working condition & materials & Mt (\%) & $\operatorname{Mad}(\%)$ & Aad (\%) & $\operatorname{Vad}(\%)$ & Fcad $(\%)$ & $\begin{array}{l}\text { Low calorific } \\
\text { value }(\mathrm{MJ} / \mathrm{kg})\end{array}$ \\
\hline \multirow[t]{2}{*}{ Blank condition } & Dry slime & 7.90 & 0.86 & 39.07 & 8.84 & 44.19 & 15.94 \\
\hline & Coal water slurry & 31.46 & 12.14 & 26.84 & 21.57 & 20.13 & 13.83 \\
\hline \multirow{3}{*}{$\begin{array}{l}\text { Working conditions of wet } \\
\text { antibiotic residues }\end{array}$} & Dry slime & 7.64 & 1.44 & 36.87 & 8.58 & 46.91 & 17.58 \\
\hline & Coal water slurry & 32.86 & 15.79 & 24.39 & 19.46 & 23.29 & 13.70 \\
\hline & Wet antibiotic residues & 60.07 & 43.23 & 18.26 & 16.29 & 5.38 & 5.71 \\
\hline \multirow{3}{*}{$\begin{array}{l}\text { Working condition of dry } \\
\text { antibiotic residues }\end{array}$} & Dry slime & 6.62 & 0.70 & 38.55 & 8.62 & 46.21 & 16.58 \\
\hline & Coal water slurry & 32.13 & 11.09 & 24.37 & 21.67 & 21.83 & 13.56 \\
\hline & Dry antibiotic residues & 10.75 & 5.17 & 27.68 & 53.01 & 8.56 & 12.69 \\
\hline
\end{tabular}

\section{Leaching experiment}

According to HJ/T 299-2007 "Solid waste-Extraction procedure for leaching toxicity-sulphuric acid \& nitric acid method," after measuring the moisture content of the sample, add a mixed solution of concentrated sulfuric acid and concentrated nitric acid with a mass ratio of 2:1 to the reagent water and adjust the $\mathrm{pH}$ to $3.20 \pm 0.05$, used as the extractant to determine the leaching toxicity of trace elements in samples. Weigh 150-200 g sample and place it in a 2-1 extraction bottle. According to the water content of the sample, calculate the volume of the required extractant according to the liquid-solid ratio of 10:1 (1/kg), and add the configured extractant. After the bottle cap is tightly closed, it is fixed on a flip-type oscillating device, the rotation speed is adjusted to $30 \pm 2 \mathrm{r} / \mathrm{min}$, and the oscillation is performed at $23 \pm 2^{\circ}$ for $18 \pm 2 \mathrm{~h}$. When gas is generated during the shaking process, open the extraction bottle in a fume hood to release excessive pressure. As in the digestion experiment, a blank group was set during the leaching experiment to eliminate the effect of trace elements in the extractant on the experimental results.

\section{Analytical method}

To explore the migration and conversion of heavy metals in the process of collaborative disposal, we used the mass balance ratio and mass distribution law of trace elements.

According to the experimental test results and the output rate of the product during the test, the output rate of trace elements in the product per unit time can be calculated. The total distribution of trace elements in the coal-fired product follows mass conservation:

$\mathrm{M}_{\mathrm{ic}}=\mathrm{M}_{\mathrm{if}}+\mathrm{M}_{\mathrm{ib}}+\mathrm{M}_{\mathrm{ia}}+\mathrm{M}_{\mathrm{ig}}$

where $M_{i c}$ is the total amount of heavy metal $i$ input, Mif is the content of heavy metal i in fly ash, Mib is the content of heavy metal $\mathrm{i}$ in the bottom slag, Mia is the total amount of heavy metal $\mathrm{i}$ in the flue gas, and Mig is the total amount of heavy metal $\mathrm{i}$ in gypsum, the amount definition:

$\mathrm{Ri}=\left(\mathrm{M}_{\mathrm{if}}+\mathrm{M}_{\mathrm{ib}}+\mathrm{M}_{\mathrm{ia}}+\mathrm{M}_{\mathrm{ig}}\right) / \mathrm{M}_{\mathrm{ic}} \times 100 \%$

$\mathrm{Ri}$ is the mass balance ratio of trace elements. It is used to verify the accuracy and reliability of field test data of coalfired power plants. Mass balance analysis of nine different heavy metals ( $\mathrm{Cr}, \mathrm{As}, \mathrm{Pb}, \mathrm{Be}, \mathrm{Mn}, \mathrm{Co}, \mathrm{Ni}$, Se, Mo) was carried out. Because the mass fraction of trace elements is usually very low, and there are fluctuations in unit load during sampling and unavoidable human errors, the mass balance rate of trace elements is $70 \sim 130 \%$ which is generally acceptable (Wang et al. 2009; Quick and Irons 2002).

The mass distribution of a trace element refers to the ratio of the mass of the heavy metal element migrated to a certain combustion by-product to the total amount of heavy metal during the migration process. According to the content of trace elements in the product and the output rate of the product, the occurrence of different trace elements during the experiment can be calculated to obtain the mass distribution rate (Honghong et al. 2008). The calculation formula is as follows:
Table 2 Content of trace elements in furnace fuel (ppm)

\begin{tabular}{lllllllll}
\hline Trace element & $\mathrm{Cr}$ & $\mathrm{As}$ & $\mathrm{Pb}$ & $\mathrm{Mn}$ & $\mathrm{Co}$ & $\mathrm{Ni}$ & $\mathrm{Se}$ & $\mathrm{Mo}$ \\
\hline Wet antibiotic residues & 23.59 & 3.99 & 8.61 & 75.60 & 4.99 & 18.34 & 2.97 & $<0.80$ \\
Dry antibiotic residues & 14.67 & 0.86 & 2.59 & 121.00 & 2.80 & 6.89 & $<0.68$ & 4.01 \\
Coal water slurry & 17.68 & 4.54 & 15.09 & 112.70 & 4.91 & 14.74 & 2.49 & $<0.80$ \\
Dry coal slime & 52.89 & 7.61 & 21.71 & 168.00 & 5.68 & 31.32 & 4.17 & 2.15 \\
\hline
\end{tabular}




$$
K_{i}=\frac{N_{i} \times V_{i}}{N_{1} \times V_{1}+N_{2} \times V_{2}+\cdots N_{4} \times V_{4}}
$$

where $\mathrm{K}_{\mathrm{i}}$ is the mass distribution rate, $\mathrm{Ni}$ is the content of heavy metal in the product, and $\mathrm{Vi}$ is the discharge rate of the corresponding product.

\section{Results and analysis}

\section{Mass balance ratio of trace elements}

The calculated mass balance of trace elements is shown in Fig. 3. The area between the dotted lines indicates that the mass balance rate is acceptable.In the course of the test, there are fluctuation of the rate of fuel in the furnace, non-uniformity in the sampling process, human error, and instrument error in the laboratory measurement process. Mo under wet residue condition is $132 \%$. The content of Mo in fuel and solid waste is at a low level, so a slight error will cause the mass balance rate to exceed the required range. The mass balance rates of all trace elements under other conditions are between 70 and 130\%. In Fig. 3, the mass balance rate basically falls between the dotted lines, which indicates that the data of this sampling experiment is accurate and reliable, and provides a basis for the analysis and discussion below.

\section{Distribution of trace elements in the combustion process}

During the combustion stage in the circulating fluidized bed furnace, the mixture of raw coal and slag is fed into the boiler at a uniform speed, and the primary air enters the combustion chamber from the air distribution plate at the bottom of the furnace. At the beginning, a reducing atmosphere is formed in the combustion area. This area is called dense phase zone. In the dense phase zone, the large particles of the bed material flow downward due to gravity. The small particles flow upward with the flue gas and enter the rare phase zone. They are mixed with the secondary air in an oxidizing atmosphere to maintain the boiler load and burning condition of the furnace during the test (Table 3).

The furnace temperature distribution of the circulating fluidized bed under different working conditions is shown in Table 4.

During the combustion of the circulating fluidized bed, the particle concentration in the dense phase zone is higher. There is a transition zone between the dense phase zone and the lean phase zone. At the same time the high particle concentration is gradually reduced to the lower particle concentration. Most trace elements are easier to volatilize and vaporize in the reducing atmosphere in the dense phase zone, and are easier to activate in the oxidizing atmosphere in the dilute phase zone. Trace elements react with oxygen to generate a higher melting point and more stable chemical oxidation and thus migrate into the ash. At the same time, there are a large number of particle maps formed by the aggregation or agglomeration of fine particles in the dilute phase zone, and these particles continue to form and adsorb other fine particles. The distribution ratios of different trace elements during the test were analyzed, as shown in Fig. 4, Fig. 5, and Fig. 6.

During the combustion in a circulating fluidized bed furnace, the main combustion zones are the lean phase zone and the dense phase zone. The slag in the antibiotic residues is high, and the mixed fuel burns quickly after entering the furnace, and the combustion share in the dense phase zone is low. During the test, the temperature in the dense phase zone was about $850^{\circ} \mathrm{C}$. The mixture of slag and coal was first burned in a reducing atmosphere between 800 and $900^{\circ}$ (Frandsen et al. 1994) .
Fig. 3 Mass balance ratio of trace element

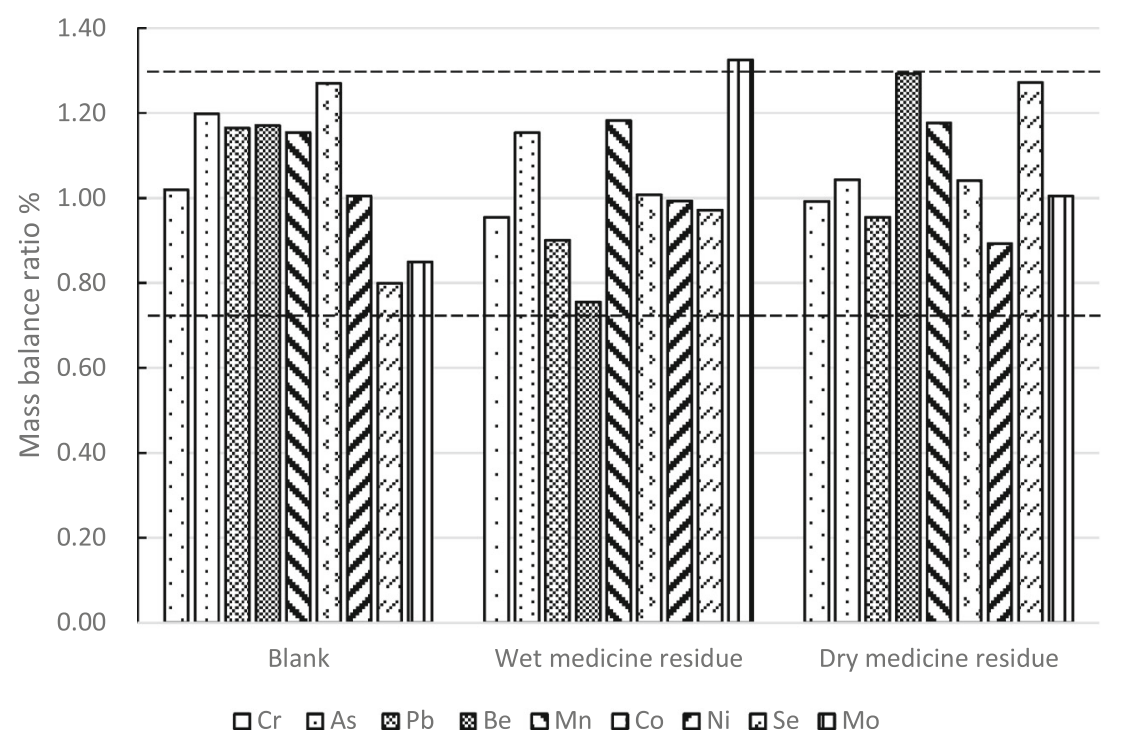


Table 3 Material input and output rate Vi

\begin{tabular}{|c|c|c|c|c|c|c|c|c|c|c|}
\hline $\begin{array}{l}\text { Working } \\
\text { condition }\end{array}$ & $\begin{array}{l}\text { Dry slime } \\
(\mathrm{t} / \mathrm{h})\end{array}$ & $\begin{array}{l}\text { Coal water } \\
\text { slurry }(\mathrm{t} / \mathrm{h})\end{array}$ & $\begin{array}{l}\text { Dry antibiotic } \\
\text { residues }(\mathrm{t} / \mathrm{h})\end{array}$ & $\begin{array}{l}\text { Wet antibiotic } \\
\text { residues }(\mathrm{t} / \mathrm{h})\end{array}$ & $\begin{array}{l}\text { Lime powder } \\
(\mathrm{t} / \mathrm{h})\end{array}$ & $\begin{array}{l}\text { Fly ash } \\
(\mathrm{t} / \mathrm{h})\end{array}$ & $\begin{array}{l}\text { Slag } \\
(\mathrm{t} / \mathrm{h})\end{array}$ & $\begin{array}{l}\text { Gypsum } \\
(\mathrm{t} / \mathrm{h})\end{array}$ & $\begin{array}{l}\text { Waste } \\
\text { water }(\mathrm{t} / \mathrm{h})\end{array}$ & $\begin{array}{l}\text { Gas } \\
\left(\mathrm{m}^{3} / \mathrm{h}\right)\end{array}$ \\
\hline Blank & 11.5 & 9.4 & 0 & 0 & 1.29 & 9.00 & 4.50 & 3.78 & 0.33 & 257588 \\
\hline $\begin{array}{l}\text { Wet antibiotic } \\
\text { residues }\end{array}$ & 12.4 & 9.3 & 0 & 0.55 & 1.25 & 9.80 & 4.70 & 3.38 & 0.37 & 242286 \\
\hline $\begin{array}{l}\text { Dry antibiotic } \\
\text { residues }\end{array}$ & 12.3 & 9.5 & 0.59 & 0 & 1.22 & 9.10 & 4.50 & 3.38 & 0.37 & 257588 \\
\hline
\end{tabular}

Due to the high melting point of $\mathrm{Cr}$ and its main compounds, it was mainly in the dense phase zone. $\mathrm{CrCl}_{3}$ decomposes into elemental substance and becomes gaseous phase; entering the transition zone, the temperature is reduced to 750 ${ }^{\circ}$. Cr reacts with sulfur compounds generated by combustion, and mainly exists stably as solid $\mathrm{Cr}_{2}\left(\mathrm{SO}_{4}\right)_{3}$. Feng (2004) used the thermodynamic calculation software $\mathrm{F}^{*} \mathrm{~A} * \mathrm{C} * \mathrm{~T}$ to make predictions. Results show that all $\mathrm{Cr}$ compounds have stable chemical and physical properties. The compounds decompose only at temperatures above $2000^{\circ} \mathrm{es}$ The predicted results show that $\mathrm{Cr}$ mainly exists in the form of $\mathrm{Cr}_{2}\left(\mathrm{SO}_{4}\right)_{3}$ and $\mathrm{CrO}_{2} \mathrm{Cl}_{2}$ at $600 \sim 800^{\circ} \mathrm{a}$; when the temperature is higher than $800^{\circ} 0$, all turned into solid $\mathrm{Cr}_{2} \mathrm{O}_{3}$ (Kashireninov and Fontijn 1998). After entering the dilute phase zone, the temperature is $825^{\circ}$ 2. During this process, $\mathrm{Cr}$ is transformed from solid $\mathrm{Cr}_{2}$ $\left(\mathrm{SO}_{4}\right)_{3}$ into $\mathrm{Cr}$ oxides such as $\mathrm{Cr}_{2} \mathrm{O}_{3}, \mathrm{FeCr}_{2} \mathrm{O}_{4}, \mathrm{CrO}_{2} \mathrm{OH}$, and $\mathrm{Cr}(\mathrm{OH})_{2}$. Cr oxides have stable chemical properties and the melting and boiling point is low, so $\mathrm{Cr}$ migrates mainly to fly ash and bottom slag (Goodarzi and Huggins 2005).

As can be seen from Fig. 4, Cr is mainly present in fly ash under three operating conditions, accounting for 64 to $72.4 \%$, and part of it is present in the slag, accounting for 26.6 to $35 \%$. After bag dust removal and static electricity dust removal, a small amount is distributed in desulfurized gypsum, desulfurized wastewater, and flue gas. Cheng et al. (2002) studied the distribution of $\mathrm{Cr}$ in the products after combustion at different temperatures, and showed that there was no significant difference in the occurrence of $\mathrm{Cr}$ in fly ash and bottom slag with the rise of temperature. More than $78.2 \%$ of $\mathrm{Cr}$ was deposited in fly ash, and $19.7 \%$ was deposited in bottom slag. This is slightly different from the experimental results in this paper. Because the circulating fluidized bed first experiences a reducing atmosphere to an oxidizing atmosphere, it is different from a pulverized coal furnace. This led to a certain difference in the occurrence of $\mathrm{Cr}$.

As is mainly present in the form of sulfide in coal powder and antibiotic residue. When it is burned in the dense phase zone, the sulfur state is converted to the gaseous state, $\mathrm{As}_{2} \mathrm{~S}_{3}$ is decomposed into $\mathrm{As}_{2}$ and $\mathrm{As}_{4}$, and the elemental As is more easily vaporized and released; Shah et al. (2008) studied the chemical forms of As during combustion. During the transition from the dilute phase zone to the transition zone, the temperature decreases, and the elemental As is converted into $\mathrm{As}_{2} \mathrm{O}_{3}$ and $\mathrm{As}_{4} \mathrm{O}_{6}$ in the oxidation state. Huang et al. (2020) studied the form of arsenic in the pulverized coalfired boiler, and found that arsenic was completely released at $1000^{\circ} \mathrm{C}$ and mainly present in the gaseous form of $\mathrm{As}_{2} \mathrm{O}_{3}$ below $1050^{\circ} \mathrm{C}$. The combustion temperature of fluidized bed boiler in this test is between 750 and 850 celsius (Zhou et al. 2016).

There is a mutual conversion relationship between the two oxides:

$\mathrm{As} 2 \mathrm{O} 3(\mathrm{~s}) \leftrightarrow \frac{1}{2} \mathrm{As} 4 \mathrm{O} 6(\mathrm{~g})$

When the particle size of the coarse particles decreases and the flue gas enters the $825^{\circ} 2$ dilute phase zone, the coal particles themselves contain some mineral components, such
Table 4 Temperature distribution in different areas of the furnace (Te)

\begin{tabular}{llll}
\hline Project & Blank condition & $\begin{array}{l}\text { Working conditions of } \\
\text { wet antibiotic residue }\end{array}$ & $\begin{array}{l}\text { Working condition of } \\
\text { dry antibiotic residues }\end{array}$ \\
\hline Dense phase zone temperature & 844.05 & 846.39 & 853.58 \\
Transition zone temperature & 780.40 & 776.07 & 782.55 \\
Lean phase zone temperature & 828.74 & 823.59 & 829.42 \\
Furnace outlet temperature & 845.92 & 850.10 & 840.50 \\
Cyclone return temperature & 871.05 & 863.29 & 876.76 \\
Main steam temperature & 544.28 & 539.98 & 542.60 \\
Feedwater temperature & 216.36 & 212.89 & 218.49 \\
\hline
\end{tabular}




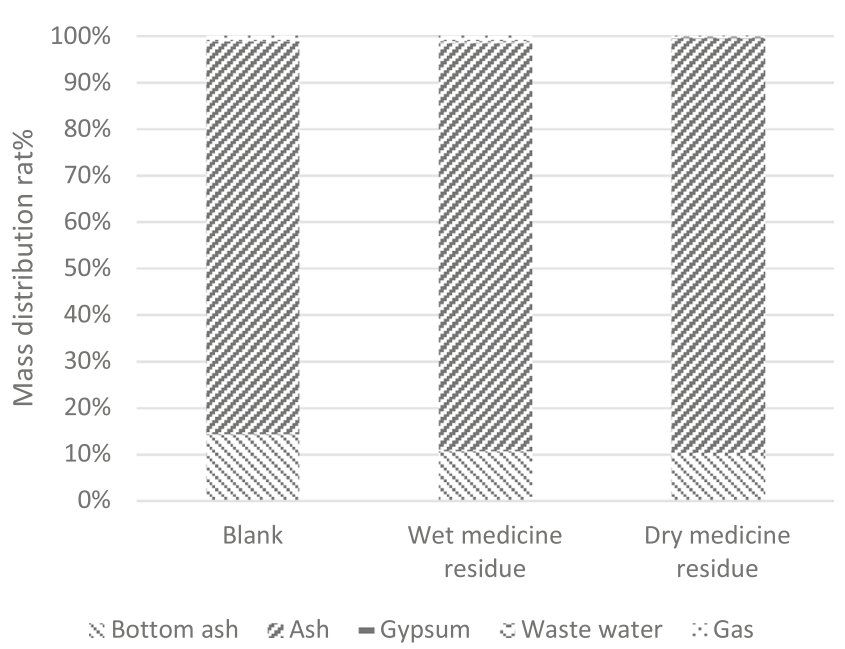

Fig. 4 Distribution of $\mathrm{Cr}$ in different products

as silicon oxide, iron oxide, and calcium oxide. In the oxidizing atmosphere in the dilute phase zone under As, it is easy for $\mathrm{Fe}_{2} \mathrm{O}_{3}$ and $\mathrm{CaO}$ to react under oxygen-rich conditions:

$3 \mathrm{CaO}(\mathrm{s})+\mathrm{As}_{2} \mathrm{O}_{3}(\mathrm{~g})+\mathrm{O}_{2}(\mathrm{~g}) \rightarrow \mathrm{Ca}_{3}\left(\mathrm{AsO}_{4}\right)_{2}(\mathrm{~s})$

$\mathrm{As}_{2} \mathrm{O}_{3}(\mathrm{~g})+\mathrm{Fe}_{2} \mathrm{O}_{3}+\mathrm{O}_{2}(\mathrm{~g}) \rightarrow 2 \mathrm{FeAsO}_{4}(\mathrm{~s})$

Because $\mathrm{Ca}_{3}\left(\mathrm{AsO}_{4}\right)_{2}$ and $\mathrm{FeAsO}_{4}$ are relatively stable in chemical properties, and the particle porosity increases at the temperature of the dilute phase zone, the diffusion resistance of As is reduced, which leads to an increase in the volatilization rate of As compounds. Therefore, As in solid waste and pulverized coal after combustion is more likely to occur in fly ash. Compared with pulverized coal furnace, more As is enriched in the bottom slag during CFB combustion. The content of As in bottom slag of pulverized coal furnace is between 1.4 and 5\% (Cheng et al. 2009; Zhao et al. 2017; $\mathrm{Fu}$ et al. 2019). In the circulating fluidized bed boiler in this experiment, the content of As in the bottom slag was 11.7 to $14.5 \%$ of the total amount.

In a reducing atmosphere at $750^{\circ} 5, \mathrm{~Pb}$ mainly comes from the decomposition of $\mathrm{PbCl}_{2}$ and exists in the form of gaseous

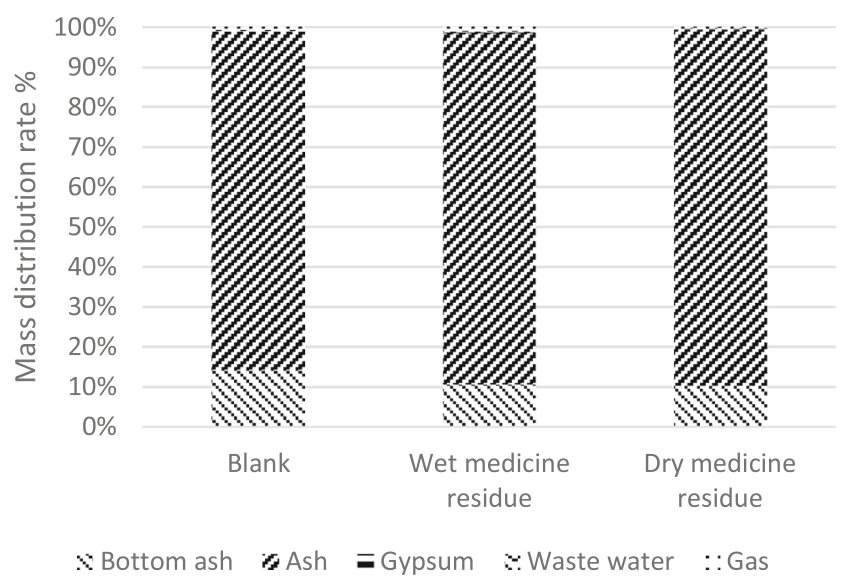

Fig. 5 As distribution in different products

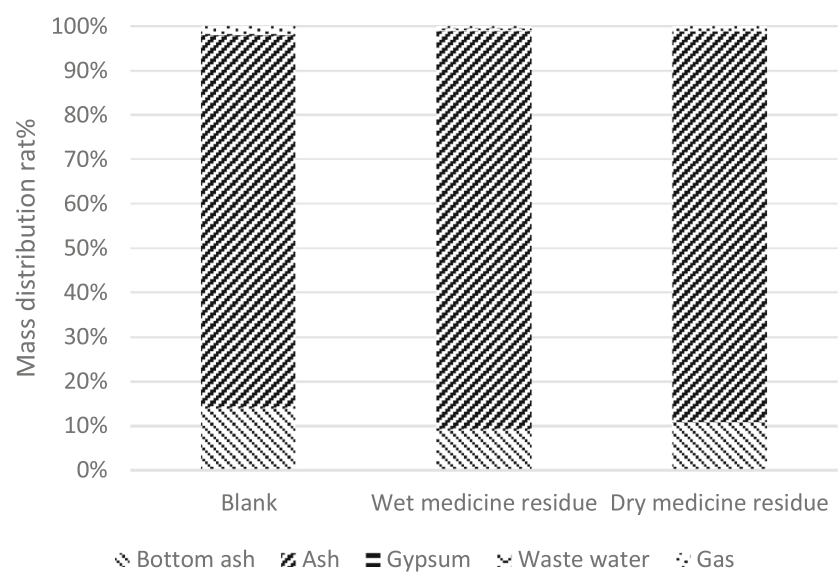

Fig. 6 Distribution of $\mathrm{Pb}$ in different products

$\mathrm{Pb}$. When the temperature of the dense phase zone in the furnace is as high as $850^{\circ} \mathrm{a}$, the decomposition of $\mathrm{PbCl}_{2}$ is accelerated and the content of $\mathrm{Pb}$ decomposed is increased. In an oxidizing atmosphere, the stability of $\mathrm{PbCl}_{2}$ is improved, and the higher oxygen concentration inhibits its volatilization, which reduces the migration ability of $\mathrm{Pb}$. With the flow of the flue gas, a part of the gaseous $\mathrm{Pb}$ volatilized into the gas phase will be in the process of flue gas cooling. Sub-micron particles are formed through homogeneous nucleation, or are readsorbed by fly ash particles through heterogeneous coagulation. At the same time, $\mathrm{Pb}$ will also chemically adsorb with fly ash, and some metal oxides on the surface of fly ash will chemically react with $\mathrm{Pb}$. The $\mathrm{Pb}$ in the flue gas is adsorbed, so that $\mathrm{Pb}$ is concentrated in the fly ash, and very few compounds of $\mathrm{Pb}$ such as $\mathrm{PbO}_{2}$ or $\mathrm{PbCl}_{2}$ enter the desulfurization system with the flue gas. It can be seen from Fig. 5 that As basically occurs in fly ash and bottom slag. The percentage of As in fly ash and bottom slag is $81.5 \%$ and $11.8 \%$, respectively. This is related to the form of compounds formed after As is burned in the furnace. The products of As after combustion are mainly oxides, with a small amount of $\mathrm{Fe}$ and $\mathrm{Ca}$ compounds. These compounds have the physical properties of high melting and boiling point, so they are easy to enter the bottom slag directly or combine with fly ash particles through homogeneous condensation and heterogeneous nucleation. The distribution of $\mathrm{Pb}$, which has similar properties with As, also has similar laws during the combustion process. As compounds have a higher melting and boiling point than $\mathrm{Pb}$ compounds and have more stable chemical properties. The content of $\mathrm{Pb}$ in fly ash reached $87.5 \%$, only $11.4 \%$ in bottom slag. The $\mathrm{Cl}$ element in the hazardous waste will cause $\mathrm{Pb}$ to be more easily enriched in the fly ash, thereby making the content of $\mathrm{Pb}$ in the fly ash and bottom slag higher.

Compared with pulverized coal furnace, CFB furnace temperature is lower. Lower furnace temperature inhibits the release of the less thermally stable compounds of arsenic. At the same time, the circulation fluidized bed combustion disturbance is severe, the material residence time is long, and the 
return system makes the compounds of heavy metal with poor thermal stability released again. In the process of CFB combustion, the yield of bottom slag is much higher than that of pulverized coal furnace, and the ratio of fly ash to bottom slag can reach 1:1. These factors lead to the distribution of As and $\mathrm{Pb}$ in the bottom slag of CFB is significantly higher than that of pulverized coal furnace.

\section{Distribution of trace elements in desulfurization system}

The WFGD system will change the emission distribution of the original trace elements in coal-fired power plants; WFGD can be used as a repurification device to capture trace elements that escape from fly ash and gas. The WFGD system can dissolve and absorb water-soluble gas phase components in the flue gas on the one hand, and on the other hand, it can also wash away some of the fine particles that are not captured by the ESP. If these trace elements enter the flue gas directly, the content of them in the flue gas will be higher than the emission standard. These particles are small in size and can be enriched in a certain amount of harmful trace elements.

During the test, the desulfurization wastewater and wet electricity wastewater were directly returned to the lime slurry pond through the pipeline to prepare lime slurry. Therefore, the materials entering the desulfurization system were limestone, flue gas before desulfurization, and process water, and the materials leaving the desulfurization system were gypsum and clean flue gas. To establish a mass balance for this process, see Fig. 7.

Figure 8 shows the distribution of trace elements in the desulfurization system among the products of the desulfurization system.

In the desulfurization system, trace elements mainly exist in lime powder and desulfurized gypsum. In the desulfurized gypsum, the trace elements occupied by $\mathrm{Cr}, \mathrm{As}, \mathrm{Pb}, \mathrm{Be}, \mathrm{Mn}$, $\mathrm{Co}, \mathrm{Ni}, \mathrm{Se}$, and Mo are $99.6 \%$ of trace elements entering the desulfurization system 96.9\%, 97.9\%, 99.1\%, 97.6\%, 99.2\%, $99.9 \%, 99.1 \%$, and $82.8 \%$. The content of trace elements in the desulfurized gypsum has reached the ppm level, while the trace elements are less distributed in the flue gas and desulfurized waste water. The various trace elements in the net flue gas only account for 0.01 to $1.95 \%$ of the trace elements in the flue gas entering the desulfurization system. Trace elements in waste water account for 1.4 to $13.5 \%$ of the amount entering the desulfurization system. Therefore, the desulfurization system has a good removal effect for trace elements, and the desulfurized gypsum has a good enrichment effect on the trace elements trapped in the gypsum slurry. After the trace elements in the flue gas have been washed by the limestone slurry in the desulfurization system, some soluble trace elements were enriched in the gypsum slurry and finally existed in the desulfurized gypsum. Table 5 shows the contents of trace elements in desulfurized gypsum under three operating conditions.

Under different working conditions, the content of trace elements in desulfurized gypsum does not vary widely. The contents of $\mathrm{Cr}, \mathrm{Mn}, \mathrm{Ni}$, and Se are in the ppm level, which are 3.89 to $5.55 \mathrm{mg} / \mathrm{kg}, 4.67$ to $5.32 \mathrm{mg} / \mathrm{kg}$, and 1.85 to 2.04 $\mathrm{mg} / \mathrm{kg}$. However, other trace elements such as $\mathrm{As}, \mathrm{Pb}, \mathrm{Be}$, $\mathrm{Co}$, and Mo are distributed in the desulfurized gypsum very little, and the detection results are all below the detection limit. It is worth noting that the contents of $\mathrm{Mn}$ and Se in gypsum increased after adding the residue. Under the two residue conditions, the Mn content increased by $9.4 \%$ and $9.2 \%$, and the Se content increased by $8.9 \%$ and $9.3 \%$, respectively. The distribution content of different trace elements in gypsum is arranged from large to small as: $\mathrm{Cr}>\mathrm{Mn}>\mathrm{Ni}>\mathrm{Se}$. The test results of this test are consistent with the results (Cordoba et al. 2012; Koralegedara et al. 2017; Li et al. 2015a; Li et al. 2015b). In order to better explore the enrichment of trace elements in the desulfurization system, the $\mathrm{pH}$ value was measured by taking out the pump slurry from the absorption tower and the pump slurry from the gypsum slurry tank during the test.

As can be seen in Table 6, after the reaction with $\mathrm{SO}_{2}$ in the desulfurization tower, the slurry in the tower and the bottom of the tower were discharged from the pump. The $\mathrm{pH}$ value of the gypsum slurry is slightly higher than 7 , which is slightly alkaline. Studies have shown that when the $\mathrm{pH}$ value of the desulfurization system slurry is greater than 7 , the molar fraction of $\mathrm{HSO}_{3}{ }^{-}$decreases sharply, while the molar fraction of $\mathrm{SO}_{3}{ }^{2-}$ increases sharply. Because $\mathrm{SO}_{3}{ }^{2-}$ cannot provide $\mathrm{H}^{+}$, it cannot enhance the dissolution process of limestone. The dissolution rate of limestone slows down significantly after $\mathrm{pH}$ value exceeds $7.0, \mathrm{Ca}^{2+}$ in the slurry, and $\mathrm{Ca}^{2+}$ are prone to react with trace elements of acid oxides. Therefore, the introduction of the WFGD system changed the emission distribution of the original trace elements in coal-fired power plants.

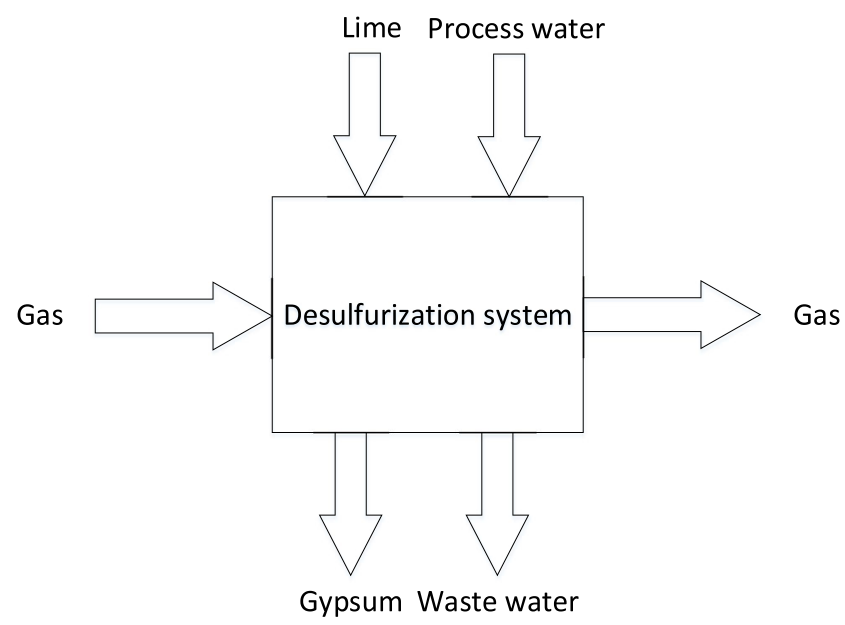

Fig. 7 Material balance of desulfurization system 
Fig. 8 Distribution of trace elements in desulfurization system

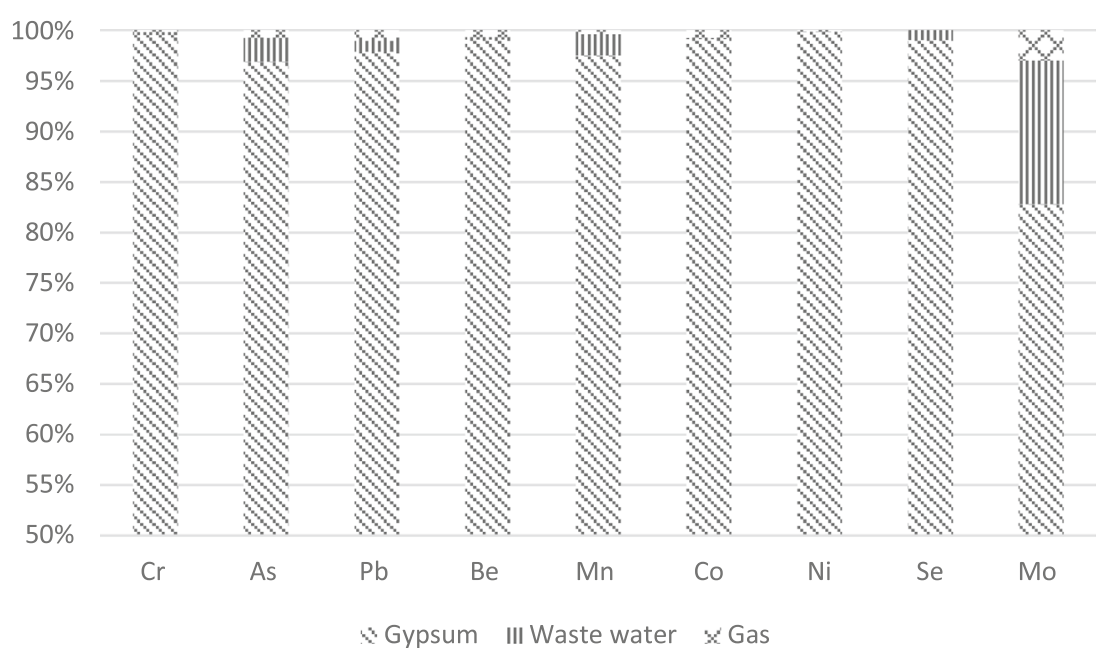

Some trace elements originally emitted directly from the flue gas into the atmosphere are captured by the WFGD system.

Because of As, its volatile content is relatively high. From the circulating fluidized bed to the desulfurization system, it mainly exists in the gas phase in the flue gas. At this time, As exists as an oxide. That is, $\mathrm{As}_{2} \mathrm{O}_{3}$, under the desulfurization system, the lower temperature $\mathrm{As}_{2} \mathrm{O}_{3}$ will gradually transform into $\mathrm{As}_{2} \mathrm{O}_{5}$ and $\mathrm{Ca}_{3}\left(\mathrm{AsO}_{4}\right)_{2}$ with acidic characteristics. When the flue gas enters the desulfurization system, the temperature is $160-170{ }^{\circ} \mathrm{C}$. Similarly, Se also exists in the form of oxides after it exits the boiler, mainly $\mathrm{SeO}_{2}$, which is liable to react with alkaline substances, thereby generating $\mathrm{CaSeO}_{4}$ in the desulfurization tower. Since Se and $\mathrm{S}$ are the same group of elements in the periodic table, they have relatively similar chemical properties, leading to the enrichment of Se in desulfurized gypsum. The two kinds of acid compounds are easy to react with the basic $\mathrm{Ca}(\mathrm{OH})_{2}$ in the limestone slurry to generate chemical properties. Goodarzi and Huggins (2005) proved that $\mathrm{Ca}_{3}\left(\mathrm{AsO}_{4}\right)_{2}$ and $\mathrm{Ca}(\mathrm{OH})_{2}$, which are relatively stable and have low solubility, are slightly soluble in water, and their solubility will decrease with the increase of the $\mathrm{pH}$ value of the solution, resulting in a greater concentration of As in the desulfurized gypsum. Not only does As and Se have a chemical reaction in the desulfurization tower, but also the homogeneous and heterogeneous condensation of the particles occurs due to the sudden drop in temperature, so that the heavy metal particles tend to be enriched in the desulfurized gypsum. After $\mathrm{Pb}$ comes out of the combustion link, it mainly exists as highly oxidizing compounds, namely $\mathrm{PbO}_{2}$ and $\mathrm{PbCl}_{2}$, and reacts with $\mathrm{SO}_{2}$ in the desulfurization tower to generate $\mathrm{PbSO}_{4}$ through an oxidation process. $\mathrm{Cr}$ is likely to exist in the form of $\mathrm{Cr}_{2} \mathrm{O}_{3}$ in the original flue gas. In the desulfurization system, $\mathrm{Cr}_{2} \mathrm{O}_{3}$ is easy to react with the desulfurization slurry under alkaline conditions to generate $\mathrm{CaCr}_{2} \mathrm{O}_{4}$ which makes $\mathrm{Cr}$ more concentrated in the desulfurization slurry and gypsum.

For semi-volatile and hardly volatile elements such as Be, $\mathrm{Co}$, and $\mathrm{Ni}$, the flue gas mainly exists in the form of particulate phase after circulating fluidized bed. After entering the desulfurization system, these particles were partially captured by the spray washing action of the limestone slurry, and the captured small particles were adsorbed and fixed by the gypsum, which led to the enrichment of these elements on the gypsum.

\section{Leaching toxicity of by-products}

Table 6 shows the results of leaching toxicity test of fly ash, slag, and gypsum in the process of collaborative disposal and the comparison of China's current hazardous waste identification standard leaching toxicity identification (GB5085.32007). The leaching concentration of all trace elements was far below the standard limit of the leaching concentration. The high content of trace elements in the residue of mixed firing led to the increase of leaching concentration of trace elements in the by-products, especially fly ash and slag. The leaching concentrations of $\mathrm{Cu}$ in fly ash and slag were 12.95 and 14.59
Table 5 Heavy metal content in desulfurized gypsum under different working conditions

\begin{tabular}{lllllllllll}
\hline Working condition & \multicolumn{1}{l}{ Heavy metal (ppm) } \\
\cline { 2 - 9 } & $\mathrm{Cr}$ & $\mathrm{As}$ & $\mathrm{Pb}$ & $\mathrm{Be}$ & $\mathrm{Mn}$ & $\mathrm{Co}$ & $\mathrm{Ni}$ & $\mathrm{Mo}$ & $\mathrm{Se}$ \\
\hline Blank condition & 5.55 & $<0.95$ & $<0.61$ & $<2.5$ & 4.67 & $<0.95$ & 2.66 & $<0.80$ & 1.85 \\
Wet antibiotic residues & 4.66 & $<0.95$ & $<0.61$ & $<2.5$ & 5.11 & $<0.95$ & 3.60 & $<0.80$ & 2.03 \\
Dry antibiotic residues & 3.89 & $<0.95$ & $<0.61$ & $<2.5$ & 5.10 & $<0.95$ & 1.65 & $<0.80$ & 2.04 \\
\hline
\end{tabular}


Table 6 PH value of desulfurization system materials under different working conditions

\begin{tabular}{lll}
\hline Working condition & Position & PH value \\
\hline Blank condition & Absorption tower & 7.73 \\
& Gypsum slurry & 7.48 \\
Wet antibiotic residues & Absorption tower & 7.81 \\
& Gypsum slurry & 7.13 \\
Dry antibiotic residues & Absorption tower & 7.05 \\
& Gypsum slurry & 7.13 \\
\hline
\end{tabular}

$\mathrm{g} / \mathrm{L}$ in blank condition, 14.79 and $15.97 \mathrm{~g} / \mathrm{L}$ in wet residue condition, and 16.58 and $16.47 \mathrm{~g} / \mathrm{L}$ in dry residue condition, which increased by $14.2 \%, 9.5 \%, 28 \%$, and $12.9 \%$ in blank condition. The leaching concentrations of $\mathrm{Ba}$ in fly ash and slag were 12.85 and $62.83 \mathrm{~g} / \mathrm{L}$ in blank condition, 16.19 and $72.78 \mathrm{~g} / \mathrm{L}$ in wet residue condition, and 19.58 and $83.65 \mathrm{~g} / \mathrm{L}$ in dry residue condition, which increased by $26 \%, 15.7 \%$, $52.4 \%$ and $33.1 \%$, respectively, compared with blank condition (Table 7). Similar to $\mathrm{Cu}$ and $\mathrm{Ba}$, the concentration of other trace elements also showed an increasing trend after the addition of burnt residue. However, the overall leaching concentration of trace elements with different by-products was relatively low, and the concentration of major trace elements in the by-product leaching solution was far lower than the relevant national standards. Therefore, in terms of leaching characteristics, under the condition of 5 6.7\% ratio of mixing and burning of drug residue, the by-products of coal burning are not hazardous wastes and can be reused. However, after mixing and burning, the inlet and outlet concentrations of different trace elements show an increasing trend.

\section{Conclusion}

(1) During the combustion process, $\mathrm{Cr}$, $\mathrm{As}$, and $\mathrm{Pb}$ are mainly present in fly ash, accounting for 64 to $87.6 \%$, and some are present in slag, accounting for 11.4 to $35 \%$. Only three trace elements are captured by the desulfurization system or follow Smoke enters the environment. The incoming fuel passes through the reducing zone and then through the oxidizing zone. The three trace elements in the reducing zone are decomposed from the common forms of chloride and sulfide into simple substances and exist in gaseous form. After entering the oxidizing zone, they form oxides with higher melting points, and oxides with different trace elements have high melting point and high boiling point. The melting point characteristics make it enriched in fly ash and slag.

(2) During the desulfurization process, trace elements are mainly concentrated in gypsum. Among them, 82.8 to $99.9 \%$ of $\mathrm{Cr}, \mathrm{As}, \mathrm{Pb}, \mathrm{Be}, \mathrm{Mn}, \mathrm{Co}, \mathrm{Ni}, \mathrm{Se}$, and $\mathrm{Mo}$ are present in gypsum, and the concentration of trace elements in gypsum has reached ppm level. The heavy metal content in the flue gas accounts for 0.01 to $1.95 \%$, indicating that the desulfurization system has a good removal effect on the trace elements studied. Volatile heavy metal compounds in the flue gas, such as $\mathrm{As}_{2} \mathrm{O}_{3}, \mathrm{As}_{2} \mathrm{O}_{5}, \mathrm{SeO}_{2}, \mathrm{Cr}_{2} \mathrm{O}_{3}$, and $\mathrm{PbO}_{2}$, react under acidic conditions of the desulfurization slurry to form the corresponding sulfate form, which is enriched in the desulfurization slurry

Table 7 Heavy metal leaching concentration in each product under different working conditions

\begin{tabular}{|c|c|c|c|c|c|c|c|c|c|c|}
\hline \multirow[t]{2}{*}{ Heavy metal } & \multicolumn{3}{|c|}{ Blank condition } & \multicolumn{3}{|c|}{ Wet antibiotic residues } & \multicolumn{3}{|c|}{ Dry antibiotic residues } & \multirow[t]{2}{*}{ Standard limi } \\
\hline & Fly ash & Slag & Gypsum & Fly ash & Slag & Gypsum & Fly ash & Slag & Gypsum & \\
\hline $\mathrm{Be}$ & 0.07 & 0.27 & 0.00 & 0.04 & 0.19 & 0.00 & 0.06 & 0.30 & 0.00 & 20 \\
\hline $\mathrm{Cr}$ & 5.18 & 4.74 & 0.04 & 3.78 & 4.35 & 0.27 & 4.26 & 5.79 & 0.23 & 15000 \\
\hline $\mathrm{Ni}$ & 3.84 & 3.25 & 0.01 & 3.22 & 3.38 & 0.03 & 3.33 & 3.79 & 0.00 & 5000 \\
\hline $\mathrm{Cu}$ & 6.45 & 7.55 & 0.08 & 4.86 & 8.08 & 0.06 & 4.64 & 9.64 & 0.06 & 100000 \\
\hline $\mathrm{Zn}$ & 12.95 & 14.59 & 0.12 & 14.79 & 15.97 & 0.16 & 16.58 & 16.47 & 0.10 & 100000 \\
\hline As & 1.02 & 2.73 & 0.01 & 0.43 & 1.87 & 0.01 & 0.60 & 2.87 & 0.01 & 5000 \\
\hline $\mathrm{Se}$ & 2.79 & 4.25 & 0.00 & 0.02 & 1.29 & 0.00 & 2.54 & 4.45 & 0.00 & 1000 \\
\hline $\mathrm{Ag}$ & 0.02 & 0.01 & 0.00 & 0.00 & 0.01 & 0.00 & 0.00 & 0.01 & 0.00 & 5000 \\
\hline $\mathrm{Cd}$ & 0.02 & 0.20 & 0.00 & 0.02 & 0.06 & 0.00 & 0.02 & 0.05 & 0.00 & 1000 \\
\hline $\mathrm{Ba}$ & 12.85 & 62.83 & 0.06 & 16.19 & 72.78 & 0.07 & 19.58 & 83.65 & 0.07 & 100000 \\
\hline $\mathrm{Hg}$ & 0.00 & 0.00 & 0.00 & 0.00 & 0.00 & 0.00 & 0.00 & 0.00 & 0.00 & 100 \\
\hline $\mathrm{Pb}$ & 0.44 & 2.30 & 0.01 & 0.42 & 3.16 & 0.02 & 0.39 & 2.64 & 0.01 & 100000 \\
\hline
\end{tabular}


and finally enters the gypsum. Hardly volatile trace elements such as $\mathrm{Be}, \mathrm{Co}$, and $\mathrm{Ni}$ exist in the form of particles in the flue gas, and are partially captured by the spray washing action of the limestone slurry, thereby being enriched in gypsum.

(3) The leaching toxicity of the by-products of the circulating fluidized bed is lower than the current standards in China when the blending ratios of the wet antibiotic residues and the dry antibiotic residues are 1:15 and 1:20, respectively. When the blending rate is less than $6.7 \%$, coal by-products are not hazardous waste and can be reused; the contents of $\mathrm{Cr}, \mathrm{Ni}, \mathrm{Cu}, \mathrm{Zn}$, and $\mathrm{Ba}$ in the products increased by 9.5 to $22.3 \%$. In addition, in the case of increasing the blending ratio, may cause harm to the environment.

Author contribution The idea and design of the research: Dahai Yan and Haiping Xiao. Literature search and data analysis: Jinlin Ge, Xinyao Li, and Zhong Liu. All authors drafted and/or critically revised the work.

Funding This project was financially supported by the Key projects of the national key research and development program [2018YFB060510104] and the National Natural Science Foundation of China [51676070].

Data availability All data and materials are available in manuscript.

\section{Declarations}

Ethics approval Not application.

Consent to publish All the authors approved the manuscript for publication.

Competing interests The authors declare no competing interests.

\section{References}

Cheng J, Xu M, Zeng H, Feng R, Qiao Y (2002) Study on oxidation kinetics of $\mathrm{Cr}$ at high temperature. CSEE 08:136-139

Cheng CM, Hack P, Chu P, Chang YN, Lin TY, Ko CS, Chiang PH, He CC, Lai YM, Pan WP (2009) Partitioning of mercury, arsenic, selenium, boron, and chloride in a full-scale coal combustion process equipped with selective catalytic reduction, electrostatic precipitation, and flue gas desulfurization systems. Energy Fuel 23(10):4805-4816

Cordoba P, Ochoa-Gonzalez R, Font O, Lzquierdo M, Querol X, Leiva C et al (2012) Partitioning of trace inorganic elements in a coal-fired power plant equipped with a wet Flue Gas Desulphurisation system. Fuel 92:145-157

Dong H, Jiang X, Lv G, Chi Y, Yan J (2015) Co-combustion of tannery sludge in a commercial circulating fluidized bed boiler. Waste Manag 46:227-233

Duan L, Cui J, Jiang Y, Zhao C, Anthony EJ (2017) Partitioning behavior of Arsenic in circulating fluidized bed boilers co-firing petroleum coke and coal. Fuel Process Technol 166:107-114
Feng R (2004) Research and comparison of chemical thermodynamics and kinetic calculation of typical trace Elements in Coal. Huazhong University of Science and Technology, Wuhan

Frandsen F, Dom-Johansen K, Rsmussen P (1994) Trace elements from combustion and gasification of coal: an equilibriumap-proach. Prog Energy Combust Sci 20:115-138

Fu B, Liu GJ, Mian MM, Sun M, Wu D (2019) Characteristics and speciation of heavy metals in fly ash and FGD gypsum from Chinese coal-fired power plants. Fuel 251:593-602

Goodarzi F, Huggins FE (2005) Speciation of chromium in feed coals and ash byproducts from Canadian power plants burning subbituminous and bituminous coals. Energy Fuel 19(3):905-915

Honghong Y, Jiming H, Lei D, Xiaolong T, Ping N, Xinghua L (2008) Fine particle and trace element emissions from an anthracite coal-fired power plant equipped with a bag-house in China. Fuel 87:10-11

Huang Y, Hu HY, Gong HY et al (2020) Research progress of arsenic, selenium and lead emission and control technology from coal-fired power plants. J Fuel Chem Technol 48(11):1281-1297

Jiang XG, Wei BJ, Hu LF, Wang RP, Song FF, Chen SQ (2020) Research status of external heat exchanger of circulating fluidized bed boiler and its application in waste incineration. Chem Ind Eng Prog 24:1-13

Kashireninov OE, Fontijn A (1998) Modeling of chromium combustion in incineration: thermochemistry of $\mathrm{Cr}-\mathrm{C}-\mathrm{H}-\mathrm{Cl}$ combustion in air and selection of key reactions. Combust Flame 113(4):498-506

Koralegedara NH, Al-Abed SR, Arambewela MKJ, Dionysiou DD (2017) Impact of leaching conditions on constituents release from Flue Gas Desulfurization Gypsum (FGDG) and FGDG-soil mixture. J Hazard Mater 324:83-93

Li J, Zhuang XG, Leiva C, Cornejo A, Font O, Querol X, Moeno N, Arenas C, Fernández-Pereira C (2015a) Potential utilization of FGD gypsum and fly ash from a Chinese power plant for manufacturing fire-resistant panels. Constr Build Mater 95:910-921

Li LJ, Zhang Q, Liu P, Bai GJ, Wu WL (2015b) Survey and analysis of heavy metals in FGD gypsum from coal-fired power plants. J Soil Water Conserv (in Chinese) 29:209-214

Liu H (2014) Analysis of hazardous waste treatment and disposal technology in china. China Homes 15:06-06

Liu J, Jiang X, Zhou L, Wang H, Han X (2009) Co-firing of oil sludge with coal-water slurry in an industrial internal circulating fluidized bed boiler. J Hazard Mater 167(1-3):817-823

Liu ZC, Zhong WQ, Shao YJ, Liu XJ (2020) Exergy analysis of supercritical CO2 coal-fired circulating fluidized bed boiler system based on the combustion process. Energy 208

National bureau of statistics (2018) China statistical yearbook. China statistics press, Beijing

Quick WJ, Irons R (2002) Trace element partitioning during the firing of washed and untreated power station coals. Fuel 81(5):665-672

Sandelin K, Backman R (2001) Trace elements in two pulverized coalfired power stations. Environ Sci Technol 35(5):826-834

Shah P, Strezov V, Prince K, Nelson PF (2008) Speciation of As, Cr, Se and $\mathrm{Hg}$ under coal fired power station conditions. Fuel. 87(10-11):18591869

Tong Lizhi, Tang Yi, Wang Feng, Hu Bin, Shi Pixing, Hu Qing (2019) Investigation of controlling factors on toxic metal leaching behavior in municipal solid wastes incineration fly ash. Environ Sci Pollut Res Int 26: (28)

Wang L (2017) Analysis of current situation of hazardous waste treatment and disposal.Green building materials 02(237):151-151

Wang SX, Zhang L, Li GH et al (2009) Mercury emission and speciation of coal-fired power plants in China. Atmos Chem Phys Discuss 10(3):1183-1192 
Zhao JY, Tang XY, Huang WH (2002) Abundance of trace elements in coal of China. Coal Geol China (in Chinese) 14:5-17

Zhao SL, Duan YF, Chen L, Li Y, Yao T, Liu S, Liu M, Lu J (2017) Study on emission of hazardous trace elements in a 350 MW coalfired power plant. Part 2. Arsenic, chromium, barium, manganese, lead. Environ Pollut 226:404-411

Zhou CC, Zhang NN, Peng CB, Cong LF, Ouyang CH, Han R (2016) Arsenic in coal: modes of occurrence, distribution in different fractions, and partitioning behavior during coal separation-a case study. Energy Fuel 30(4):3233-3240.
Zhu G, Zhao C, Chen H, et al (2009) The emissions of PAHs and trace elements from co-combustion of petrochemical sludge with coal in $\mathrm{CFB}$ incinerator[M]// Proceedings of the 20th International Conference on Fluidized Bed Combustion 40(01):68-72

Zhu SJ, Zhu JG, Yu QG, Pan F, Zhang Y, Liu W (2019) NO emissions under pulverized char combustion in $\mathrm{O}_{2} / \mathrm{CO}_{2} / \mathrm{H}_{2} \mathrm{O}$ preheated by a circulating fluidized bed. Fuel 252:512-521

Publisher's note Springer Nature remains neutral with regard to jurisdictional claims in published maps and institutional affiliations. 